\title{
A CITAÇÃO NA CHANCELARIA - A COMUNA DE ROMA NO MEDIEVO ${ }^{1}$
}

\section{Citation in Chancellery - The commune of Rome in Middle Ages}

\author{
ORCID: https://orcid.org/0000-0001-9519-0166 \\ E-mail: dario.internullo@ virgilio.it
}

Pesquisador da Università degli studi Roma Tre - Dipartimento di Studi Umanistici

Recebido em: 01/07/2020

Aprovado em: 05/08/2020

\begin{abstract}
Resumo: $\mathrm{O}$ artigo discute alguns aspectos retóricos das atas públicas provenientes da comuna de Roma (o Senado) entre os séculos XII e XIV. Particularmente, analisando as citações que emergem de tais atas (Cassiodoro, Riccardo da Pofi, Pier delle Vigne), reconstrói algumas práticas escriturárias da chancelaria romana e detecta a presença de determinados manuscritos nesse ambiente.
\end{abstract}

Palavras-chave: Retórica, Citações, Roma medieval, Cassiodoro.

Abstract: The article discusses some rhetorical aspects of public documents issued by the Roman Commune (the Senate) between the twelfth and fourteenth century. In particular, it analyzes citations emerging from these acts (passages from Cassiodorus, Richard of Pofi, Pier delle Vigne) in order to reconstruct some writing and documentary practices of the Roman chancery as well as to detect the presence of certain manuscripts within these environments.

\section{Keywords, Rhetorics, Citations, Medieval Rome, Cassiodorus.}

Riassunto: L'articolo discute alcuni aspetti retorici degli atti pubblici emanati dal comune di Roma (il Senato) tra XII e XIV secolo. In particolare, analizzando le citazioni che emergono da tali atti (Cassiodoro, Riccardo da Pofi, Pier delle Vigne), arriva a ricostruire alcune pratiche scrittorie della cancelleria romana e a individuare la presenza di determinati manoscritti all'interno di questi ambienti.

Parole chiave: Retorica, Citazioni, Roma medievale, Cassiodoro. 


\section{Historiografia, métodos, questões}

Quando se pretende refletir de maneira articulada e interdisciplinar sobre uma temática de ampla envergadura, como é justamente o caso das citações, ideias interessantes podem surgir também no que respeita aos historiadores, mais precisamente, a algumas reflexões acerca de um tipo de textos (testemunhos, se quisermos) ainda pouco praticado do ponto de vista da citação, embora rico em potencial nesse sentido: a documentação epistolar pública do medievo tardio. Uma documentação, vale dizer, produzida pelas chancelarias de autoridades como reis, imperadores, papas e comunas no que tange a precisos vínculos formais e, paralelamente, em perfeita correspondência com os tratados de teoria epistolar da época. ${ }^{2}$

Tais testemunhos, por muito tempo estudados quase exclusivamente por historiadores das instituições e por diplomatistas, foram muito recentemente reavaliados também como fonte útil à história da cultura e das práticas culturais, e isso sobretudo por mérito de uma volumosa pesquisa de Benoît Grévin sobre as cartas de Pier della Vigna e sobre a sua difusão no Ocidente tardomedieval. De fato, estudando o caso particular de Pier della Vigna, o historiador francês conseguiu demonstrar como, a partir das últimas décadas do Duecento, as cartas do grande dictator de Frederico II começaram a circular, sob a forma de coletâneas de modelos epistolares (ou summae dictaminis), em todo o Ocidente e, frequentemente estudadas em ambientes escolares, foram depois utilizadas intensamente, nas mais importantes chancelarias da Europa, como referência de escritura retórica até boa parte do Quattrocento, alimentando um fenônemo de homogeneização da linguagem política ocidental. ${ }^{3}$ Dessa imponente pesquisa, interessa-nos destacar o método utilizado para compreender a difusão da summa de Pier della Vigna: de fato, Grévin procurou identificar citações implícitas e reelaborações das cartas do dictator no âmbito da documentação pública das maiores chancelarias da Europa. Assim, utilizou um método de análise geralmente praticado por estudiosos de literatura, mas recentemente levado em consideração também por alguns historiadores avessos aos métodos da chamada arqueologia do texto medieval. ${ }^{4}$ Dessa maneira, para dar um exemplo, ter encontrado, nos diplomas do rei da França, três, cinco, dez linhas tomadas de empréstimo às cartas do famoso dictator, e certamente readaptadas à circunstância, permitiu ao estudioso não apenas constatar a presença de um manuscrito contendo a summa dictaminis no âmbito da chancelaria real, mas também compreender as modalidades de que se valeram os funcionários para reelaborar o seu modelo segundo as contingências do momento e a ideologia da instituição política que representam. ${ }^{5}$ Em suma, a pesquisa e a identificação de tais citações em particular permitem trazer à luz a fisionomia e o dinamismo cultural de grupos e ambientes profissionais específicos.

Obviamente, Pier della Vigna não é o único homem de cultura a se tornar referência nas chancelarias: seu caso pode efetivamente ser colocado em paralelo com o de outros grandes dictatores, como Tommaso da Capua, Riccardo da Pofi, Guido Faba e outros ainda, os quais, por sua vez, combinaram modelos muito mais antigos e presentes havia muito nas chancelarias, Cassiodoro em primeiro lugar. Mesmo a identificação de empréstimos de suas epístolas, portanto, pode nos dizer muito sobre algumas das práticas escriturárias da chancelaria em consideração, em particular sobre a composição 
de escrituras retóricas da diplomacia, e sobre a cultura dos funcionários que atuam em seu âmbito.

Ora, se cada uma dessas antologias epistolares se beneficiou de numerosos estudos, situáveis no contexto de uma recente revalorização historiográfica abrangente dos tratados epistolares tardomedievais, a relação entre tais coletâneas e as práticas de chancelaria é um tema ainda pouco estudado nos seus aspectos mais concretos, sobretudo no que respeita à Itália centro-setentrional, ou seja, a Itália comunal e senhoril. ${ }^{6} \mathrm{O}$ fato é compreensível, se pensamos na grande variedade de experimentos políticos que, no curso de dois séculos e meio, se manifestaram nesta área e, portanto, na dificuldade de confrontar realidades e fontes tão numerosas quanto tipologicamente variadas e situadas diversamente no espaço. Para as reflexões que propomos aqui, então, examinaremos um estudo de caso pertencente a esta área: o caso da comuna romana.

Apesar de diversos aspectos da Roma medieval ainda serem vítimas de antigos paradigmas historiográficos capazes de ofuscar o que determinam as fontes, e apesar de a história da comuna romana ser marcada por enormes lacunas, ao menos neste contexto a cidade constitui um caso afortunado, porque, efetivamente, foram identificados diversos usos das cartas de Pier della Vigna na produção epistolar desta comuna. Em particular, eles emergem nas cartas compostas a título oficial por Cola di Rienzo no período em que ele dirigiu a comuna, depois de dar um golpe de estado (1347). ${ }^{7}$ No entanto, Cola é um personagem bastante complexo, seja do ponto de vista intelectual ou do político, sem contar que seu governo é considerado por muitos como um parêntese excepcional na história da Urbe. Assim, será necessário estender a análise ao mais amplo corpus da documentação pública romana no período comunal (1143-1398), se desejamos compreender plenamente práticas de escritura retórica internas à chancelaria romana.

O objetivo deste estudo é estender a análise dos reempregos textuais a um número de escrituras epistolares públicas suficientemente amplo para cobrir todo o arco cronológico de sua história. Mais precisamente, busca-se identificar, no âmbito da documentação, palavras, frases e passos tomados de empréstimo a modelos epistolares preexistentes e readaptados à circunstância. Os resultados de tal pesquisa serão apresentados neste espaço. A um parêntese preliminar, dedicado a fornecer ao leitor algumas coordenadas úteis para se orientar na documentação em consideração, seguirá a ilustração de alguns exemplos significativos no âmbito de considerações mais gerais sobre as práticas em questão, para concluir com os ganhos historiográficos que esse tipo de análise comporta e, paralelamente, com uma nota sobre o potencial de seu método.

Quem são os responsáveis pelas escrituras retóricas romanas? Em qual contexto político operaram? Que modelos utilizaram para compor suas escrituras retóricas? De que modo os reelaboraram? De maneira mais geral, o que um reemprego textual de um documento de chancelaria pode nos dizer? Essas são as principais questões sobre as quais versarão as páginas que seguem.

\section{A comuna romana e suas escrituras entre os séculos XII e XIV}

A data de nascimento da comuna romana é fixada pelos historiadores no verão de 1143, momento em que, no contexto de uma forte crise política, um amplo grupo de cidadãos (ainda hoje se debate sobre sua exata natureza) consegue tornar institucional 
uma estrutura de governo nova e alternativa em relação à dos pontífices, que em Roma dominavam a cena política desde o século VIII, se não antes. As fontes, romanas ou não, dão o nome de Senatus a essa nova instituição, a qual corresponde concretamente, porém, a uma comuna em diversos aspectos semelhantes a tantas outras da Itália centrosetentrional. A partir desse momento, no âmbito de um palácio construído no Capitólio, oficiais chamados senatores administram, assistidos por um vasto número de juízes e notários, os principais setores da vida pública: do fisco às provisões, da ordem pública à justiça, do exército à política territorial.

Em dois séculos e meio de história, o Senado protagonizou diversas transformações: a uma primeira fase, em que um colégio de 56 senadores dirige a comuna, no final do século XII, segue uma segunda fase, em que governa uma dupla de senadores. Esse estado de coisas muda novamente em seguida ao parêntese, tão breve quanto incisivo, do governo de Cola di Rienzo, notário de origem humilde que chegara ao governo da comuna em 1347, não com o título de senador, mas de pacis iustitieque tribunus. Poucos anos depois de sua morte (ocorrida em 1354), o governo de Roma será novamente exercido por um senador, desta vez único, recrutado exclusivamente fora de Roma, bem como assistido por sete reformatores reipublice. A história da comuna romana termina em 1398, quando os pontífices tomam novamente as rédeas da política citadina, mantendo o governo da cidade até $1870 .^{8}$

Do ponto de vista social, até a metade do Duecento os principais atores da política romana provêm de um grupo expandido de famílias pertencentes ao chamado estrato da nobreza ou dos milites, ou seja, aqueles que dispunham de recursos que lhes permitiam a manutenção de um cavalo de guerra. A partir daquele momento, em contrapartida, será um grupo restrito de famílias nobres protagonistas de uma ascensão social extraordinária, os chamados barões, a deter o monopólio do cargo senatorial. Depois do parêntese do tribunado de Cola, os verdadeiros protagonistas da política serão indivíduos pertencentes a ordens sociais muito distantes da nobreza, como artesãos, joalheiros, peixeiros etc. É o chamado povo de Roma, a que também o tribuno pertencia. Desde seu nascimento a comuna foi dotada de uma imponente chancelaria, no âmbito da qual um número considerável de notários teve um grande trabalho para produzir os escritos que podiam servir à administração citadina. Esses notários provinham da ordem sócio-profissional dos scriniarii sanctae Romanae Ecclesiae, um grupo de indivíduos altamente alfabetizados que se desenvolvera em torno ao papado altomedieval e que havia muito dominava o panorama da produção escrita romana, especialmente no âmbito privado. ${ }^{9}$ Quando os romanos refundaram o Senado, escolheram imediatamente essas figuras para gerir da melhor maneira possível as exigências escriturais de suas instituições. Os scriniarii (que a partir do Duecento se chamarão notarii) dominavam perfeitamente o latim escrito e eram capazes de utilizá-lo com notável versatilidade; possuíam, ademais, conhecimentos técnicos bastante profundos dos formulários e do direito. A esse grupo pertencem os primeiros idealizadores dos textos sobre os quais nos deteremos, enquanto a sua tradição cultural é certamente a aspiração de seus epígonos. ${ }^{10}$ Não dispomos de dados muito específicos sobre esses indivíduos, uma vez que a documentação nunca explicita com clareza a quem deve ser atribuída a construção retórica do texto: cabe pensar, porém, que se trata dos notários que ocupavam os graus mais elevados na chancelaria, como o cancellarius, os scribesenatus, no Trecento talvez ainda o dictator e os notários da Camera Urbis. 
No mais amplo sistema documental da comuna romana, as epístolas públicas pertenciam ao conjunto das escrituras oficiais, textos delicados e por isso munidos de um complexo ditado retórico:

“ [...] atas de relevância externa, como concessões, tratados, convenções, privilégios e, em particular, sentenças: ou seja, escrituras que tinham a função de, conforme a necessidade, ratificar, formalizar e, sobretudo, notificar e tornar executivas as decisões do Senado, e por isso dotadas de uma autoridade e de um formalismo particulares."11

Trata-se de uma parte mínima e bastante fragmentária do que devia ser a produção escritural dos notários, mas é uma parte preciosa, se pensamos que todas as escrituras produzidas pela comuna e destinadas a permanecer em seu âmbito (os registros e os cartulários, testemunhos das atividades de cada ofício), assim como os demais materiais conservados no palácio capitolino (documentos recebidos, livros de direito, formulários e modelos epistolares), desapareceram junto com o arquivo comunal já no começo da idade moderna. As atas oficiais, em contrapartida, compostas para serem expedidas para fora do Capitólio, são as únicas a ter sobrevivido ao naufrágio e encontram-se hoje, no original ou em cópia, nos arquivos dos sujeitos jurídicos a quem eram destinadas. ${ }^{12}$

\section{Os reempregos textuais: de Frederico I a Cassiodoro}

Ainda que a vida citadina de Roma seja formalmente administrada, por dois séculos e meio, pelas instituições comunais, não se pode esquecer que uma forte disputa envolveu estas últimas e os pontífices durante todo o período considerado, e que estes continuaram a nutrir o desejo de dirigir a cidade; em consequência, não faltaram momentos em que os papas conseguiram efetivamente ter um peso muito forte no jogo político citadino. O primeiro dos nossos documentos diz respeito justamente a um desses momentos. Redigido em 1188 sob a forma de privilégio, ele coincide com a elaboração por escrito de um acordo político alcançado entre os romanos e Clemente III, no âmbito do qual o pontífice consegue obter uma ata formal de fidelidade da parte do Senado e são sancionadas prerrogativas para ambas as partes, na verdade muito mais vantajosas do ponto de vista pontifício do que do senatorial. ${ }^{13} \mathrm{O}$ que nos interessa se encontra no preâmbulo, a parte introdutória do documento, mais aberta aos experimentos retóricos e geralmente enriquecida de citações. ${ }^{14}$ De fato, os notários da comuna decidiram redigi-lo recorrendo a modelos diversos. Para a seção de abertura, dedicada a exaltar a importância da escritura seja para exprimir a grandeza do Senado, seja para construir uma memória perpétua da paz, eles atentaram aos preâmbulos imperiais de Frederico Barba-Ruiva, do fim dos anos sessenta. Como notou o historiador Jürgen Petersohn, na Roma da época - e mais precisamente na Igreja de S. Bartolomeo sull'Isola Tiberina - conservava-se pelo menos um documento solene que se abria com um ditado quase idêntico ao do privilégio senatorial:

"Dignitas senatus populique Romani in optimum statum roboratur et reipublice nimium confert, si pacis concordiam inter sacrosanctam Ecclesiam et inclitam Urbem firmiter stabilitam ad posterorum memoriam sollempni scripturarum exaratione reducamus, ne forte per negligentiam vel socordiam inestimabilis pacis veritas temporis lapsu depereat, que sue 
excellentie prerogativa ab omnibus est tam colenda quam perpetuis temporibus observanda."

"Dignitas imperii Romani in optimum statum roboratur et reipublice plurimum confert, si ea que celebri digna sunt memoria in scriptis redigantur et ad omnium posterorum noticiam congruo ordine transferantur, ne forte per negligentiam sive per ignorantiam rerum gestarum veritas depereat vel per successione temporum totus ordo rerum dubius apud homines relinquatur." 15

O documento imperial dizia respeito a um caso mais religioso do que político: de fato, colocava sob a proteção imperial o traslado das relíquias de São Bartolomeu ocorrido na igreja homônima, ocorrida muito tempo antes, mas sempre por obra de um imperador germânico. Em ambos os casos, porém, se tratava de eventos dignos de se transmitir à posteridade, e foi assim que a arenga imperial foi usada, obviamente atentando à substituição de Imperium por Senatus Populusque e à inserção de detalhes mais úteis à identificação do texto com um acordo de paz. ${ }^{16}$

Para uma comuna nova que, como a de Roma, buscava continuamente legitimarse perante o seu bispo, mas não dispunha de uma consolidada tradição cultural própria, a retórica imperial constituía um ótimo modelo para construir uma linguagem que se colocasse no mesmo plano da instituição rival.

No entanto, os notários da Urbe extrapolaram o Império, tomando direções menos previsíveis para o historiador. De fato, no preâmbulo do documento, segue uma espécie de hino à paz, dedicado a explicitar as vantagens que ela pode comportar: fertilidade dos campos, conforto, ganhos e justiça para os inimigos. Ora, se Petersohn tinha razão ao hipotisar que tal seção era um reemprego textual de documentos fredericanos perdidos, uma pesquisa mais aprofundada permitiu identificar seu modelo entre as Variae de Cassiodoro, mais precisamente na III, 25, escrita em nome de Teodorico como comes Simeônio:

"Per habundantiam namque pacis auxiliante Deo patrie crescit defensio et Romane Ecclesie atque Urbis egregie dignitas conservetur illesa. Hinc agrorum fertilitas procreatur que in usum humane vite multiplici commoditate porrigitur, per quam equidem nobis et vobis ceterisque illam conservantibus utilitates et lucra generantur quamplurima et hostibus nostris vestrisque male merentibus digna preparantur exitia."

"Praeterea ferrarias praedictae Dalmatiae cuniculo te veritatis iubemus inquirere, ubi rigorem ferri parturit terrena mollities et igne decoquitur ut in duritiam transferatur. Hinc auxiliante Deo patriae defensio venit, hinc agrorum utilitas procuratur et in usus humane vitae multiplici commoditate porrigitur. Auro ipsi imperat et servire cogit locupletes pauperibus constanter armatis. Convenit itaque hanc speciem diligenti indagatione rimari, per quam et nobis generantur lucra et hostibus procurantur exitia." $" 17$ 
Na Varia, o rei godo havia ordenado ao comes Simeônio que fosse à Dalmácia para examinar, através de escavações, as mineiras da região, com vistas à extração de ferro. É graças a esse material, escreve o antigo funcionário, aludindo à possibilidade de fabricar armas, que é possível defender a pátria, e é também graças a esse material que é possível cultivar os campos, aludindo aqui, desta vez, aos instrumentos agrícolas. Partindo do ditado da carta, os notários da comuna romana reelaboraram o texto, fazendo que os conceitos expressos (patriae defensio e agrorum utilitas, agora tornado fertilitas) fossem associados não mais ao ferro da Dalmácia, mas à paz que os senadores estipularam com o pontífice. É a paz, agora, é claro, que faz que os campos sejam férteis e que a pátria continue bem defendida. $\mathrm{O}$ exemplo mostra uma operação complexa e mesmo bastante audaciosa, uma vez que reconfigura algumas imagens associadas ao ferro numa direção quase contrária à do modelo, aproximando-se, por fim, à versátil cultura pragmática dos notários romanos.

A segunda ata a analisar é datada de 1244, momento em que a comuna está nas mãos de duplas de senadores provenientes das fileiras do baronato romano. Neste caso, o documento, outro privilégio redigido em nome de Annibaldo Annibaldi e Napoleone Orsini, contém a confirmação das prerrogativas que, vários anos antes, o senador Annibaldo havia concedido aos cônegos de São Pedro, concernentes à jurisdição, às sepulturas e às atividades econômicas, a que se acrescentam agora algumas proibições para quem quer que tenha a intenção de praticar comércio nas proximidades das basílicas. Um privilégio de tal natureza, tratando de uma das mais importantes igrejas de Roma, carecia de um preâmbulo altissonante, capaz de representar os senadores como figuras ao mesmo tempo respeitosas da esfera sacra do divino e temíveis no que concerne aos laicos que lhe eram subordinados: não se poderia ter escolhido modelo melhor do que a Varia VIII, 24, com a qual o rei Atalarico havia concedido ao clero romano uma série de privilégios fiscais e jurisdicionais, bastante aplicáveis àqueles em questão:

"Tanto divinitati plurima debemus, quanto a ceteris Romane Urbis mortalibus in laycali ordine constitutis nunc maiora suscepimus. Nam quid simile rependat Deo qui senatorie dignitate potitur, que pars est corporis imperialis? Sed licet pro tanto munere nichil compensari posset idonee, ipsi tamen gratia redditur, dum in servientibus honoratur. Namque inter cetera loca Divino cultui deputata basilicam Beati Petri, in qua Domino militatis, volumus et debemus in omnibus et per omnia venerari, quia is civis gaudet vocabulo et spetiali protectione letatur [...]. Et sedes eius toto orbe mirabilis proprios tegit affectione cultores, que, etsi generalis mundo sit prestita, nobis etiam et Romanis cognoscitur et localiter attributa tenemus, nempe aliquid sanctorum apostolorum proprium, quando confessiones illas quas videre universitas appetit, Roma felicior in suis finibus habere promeruit; nil quoque timemus, talibus dum sumus patronis muniti."

"Tanto divinitati plurima debemus, quanto a ceteris mortalibus maiora suscipimus: nam quid simile rependat Deo, qui potitur imperio? Sed licet pro tanto munere nihil compensari possit idonee, ipsi tamen gratia redditur, dum in servientibus honoratur. Itaque flebili aditione causamini hoc fuisse longae consuetudinis institutum, ut, si quis sacrosanctae Romanae ecclesiae servientem aliqua crederet actione pulsandum. [...] Sedes illa toto orbe mirabilis proprios tegat affectione cultoresquae, licet generalis mundo sit praestita, nobis etiam cognoscitur et localiter 
attributa. Tenemus aliquid sanctorum apostolorum proprium, si peccatis dividentibus non reddatur alienum, quando confessiones illas quas videre universitas appetit, Roma felicior in suis sinibus habere promeruit. Nihil ergo timemus talibus patronis si oratio non desistat antistitis."

O começo da epístola de Cassiodoro foi retomado quase à letra pelos notários da comuna, salvo o acréscimo de algumas especificações: os mortais tornam-se agora aqueles que pertencem à ordem dos laicos, ou seja, aqueles aos quais o privilégio destina algumas proibições; enquanto o Império é substituído pelo Senado, definido, em todo caso, como parte do corpo imperial, segundo uma praxe que mostra bastante bem seja uma certa continuidade com a tradição chanceleresca do século XII, seja a ideia, extremamente soberba, que os senadores e seus profissionais da escritura faziam da própria instituição. Um pouco mais adiante, no texto, uma seção dedicada a exaltar a cidade de Roma e sua ligação com os apóstolos reutiliza uma outra Varia, a XI, 2, em que Cassiodoro, recém-nomeado prefeito do pretório, escreve em tom alegre ao papa João II para informá-lo de tal nomeação.

\section{Os reempregos textuais: Pier della Vigna}

Com os documentos que seguem, passamos à Roma do Trecento, uma Roma que assiste a transformações importantes, entre as quais o afastamento da Cúria do território do Lácio por mais de sessenta anos e a extensão do acesso à cultura escrita, e consequentemente ao notariado e a outras profissões de natureza intelectual, mesmo a pessoas de extração social modesta. ${ }^{19}$ De nossa ponto de vista, a novidade mais interessante é o fato de neste período, no palácio senatorial, os notários terem à disposição novos instrumentos para suas escrituras retóricas: as summae dictaminis, ou seja, as coletâneas de modelos epistolares tomadas à produção dos mais famosos funcionários da chancelaria do Duecento.

Em 1342, chega a Avignon uma embaixada composta de diversos representantes da nobreza romana, para conferir a senhoria vitalícia sobre Roma (tratava-se de uma ata puramente formal) ao pontífice Clemente VI; na verdade, o objetivo mais concreto era restituir a Roma o papel de capital da cristandade que lhe respeitava, invocando o retorno do papa e a antecipação do jubileu. ${ }^{20}$ Embora sem retornar a Roma, poucos meses depois o papa decidiu concordar com a antecipação do jubileu, o que provocou nos romanos uma alegria imensa. Os embaixadores da nobreza, entre os quais se contavam um senador e diversos funcionários da comuna, decidiram então redigir um relato da embaixada bastante retórico, em que o mundo inteiro deveria rejubilar-se pelo feliz evento:

"Exultet in gloria virtus Altissimi, resultet beatorum spiritum ierarchia, iocundetur populorum turba et pro tanti doni leticia mundus gaudeat universus! [...] honor et tripudium apud omnes populos cum exultacione et laudum preconio ab omnibus exolvatur et dies festus cum ingenti leticia devocius ab omnibus celebretur." 
"Exultet iam universa turba fidelium, exultet totum collegium dilectorum, exultet inter ceteros vester animus, et pro tanta victoria principis precipue gaudeatis! [...] Exultet iam romani culmen Imperii, et pro tanta victoria principis mundus gaudeat universus [...] Quapropter imperiale festum victorie sollempni gaudio fideles populi celebrantes, de tanti trophei preconiis ingenti letitia gaudeatis." 21

Para construir tal imagem, quem redigiu o texto tinha à disposição a Summa dictaminis de Pier della Vigna, da qual reelaborou uma carta relativa à vitória de Manfredi contra o exército papal (sic!) em 1254 e uma segunda relativa ao anúncio da vitória de Frederico II contra as tropas comunais lombardas em Cortenuova. O todo, obviamente (e verossimilmente com alguma dificuldade), buscando eliminar qualquer referência ao Império e ao imperador. É difícil reconstruir o contexto de composição deste documento, porque, ao que parece, ele foi preparado no âmago da embaixada a Avignon e não na chancelaria romana. Porém, é plausível que os nobres romanos e seus notários, pensando nas exigências de escritura relativas a sua missão, tenham tratado de ter consigo todo o instrumental útil a tal fim; e entre pergaminhos, registros, cálamos e formulários, devia encontrar-se também a antologia do grande logoteta de Frederico II.

O documento da embaixada da nobreza não é o único a fazer uso desses novos e eficazes instrumentos. De fato, boa parte da documentação oficial produzida em nome de Cola di Rienzo, depois que este tomou o poder, em maio de 1347, apresenta reelaborações das cartas de Pier della Vigna. Entre os muitos exemplos identificados por Grévin em sua pesquisa, serão citados aqui os mais límpidos, ou seja, os das cartas que o tribuno mandou enviar à comuna de Florença para promover solicitações de auxílio militar contra as formas adversas dos barões do Lácio. Numa delas, contendo, ademais, um relato da vitória do exército de Cola sobre as tropas do prefeito de Roma, Giovanni di Vico, o autor do texto procedeu a um acurado jogo de recomposição a partir de um boletim de vitória sobre a tomada de Faenza por parte de Frederico II (1241):

"Adaucte a spiritu sancto continue nostre prosperitatis auspicia, quibus misericorditer Dominus dirigit et protegit gressus nostros, amicitie vestre significamus ad gaudium ut sicut estis laborum nostrorum amicabili et filiali devotione participes, nostre quietis et gaudii non sitis expertes. Sane Iohannes de Vico, Urbis prefectus, contra quem per victoriosum exercitum Iustitie mucrone processimus, non valens ulterius se tueri, personaliter ad obbedientam nostram venit, et nostros humiliter prostratus ad pedes veniam petiit reverenter, roccha Rispampani restituta. Nosque de errantium conversione et reductione letantes et misericordia uti cum eo et aliis disponentes, ipsum benigne recepimus et clementer, et prestito per eumdem de parendo mandatis sancte matris ecclesie, sedis apostolice, Romani populi atque nostris debito iuramento in pleno publico et solempnissimo parlamento ipsum petentem suppliciter restituimus de plenitudine gratie ad prefectoriam dignitatem et singulos pristinos ad honores, ita eum benigne tractantes, ut victus et nostram misericordiam prosecutus nil gratius nilque suavius iugo pie Romane iustitie sentiat humiles experiri."

“Adaucte nobis continue felicitatis auspicia, quibus dextera Domini prosequitur gressus nostros, desiderium vestrum voluimus non latere. Cum enim in obsidione Faventie preterita hieme fixa fuerint victricia nostra castra et insultibus propter asperitatem temporis non pateret [...] verni temporis 


\begin{abstract}
adveniente temperie, cum non confiderent ulterius se tueri, misericordiam nostram tandem humiliter implorarunt et die [...] cum omni devotione se ad mandata nostra convertens, quamquam suis diffisa meritis, de nostra tamen, que suis preponderabat excessibus, pietate confisa dictioni nostre colla subiecit, et corporalis fidelitas debite prestito iuramento et omnibus aliis illicitis iuramentis, que fecerat, penitus abiuratis. Nos igitur, [...] civitatem eamdem et cives eius in gratia nostra clementer accepimus et reos absolvimus ac offensas remisimus, quas patrarant, captivis eorum liberaliter liberatis; et tamdem eis de nostra gratia confidentiam dedimus, ut victi nostramque misericordiam consecuti victorie nostre denuo congaudeant, et nichil dulcius nichilque suavius iugo Imperii sentiant experiri [...] Que omnia vobis significamus ad gaudium, ut sicut estis nostrorum successuum avidi, sic sitis participes triumphorum."
\end{abstract}

Em seu desenvolvimento narrativo, o texto segue fielmente a carta de Pier della Vigna, seja em algumas partes específicas, como o preâmbulo e o encerramento da narração, seja na extrutura geral, até o momento em que Giovanni di Vico se submete, depois de ser perdoado, ao jugo da pia justiça romana. Um conceito, este, sem dúvida inspirado no jugo do império tão bem exaltado do dictator de Frederico II.

Em outro documento, afim ao precendente pela forma, conteúdo e destinação, a captatio benevolentiae do preâmbulo é abertamente tomada de empréstimo, com reelaborações bastante leves, à carta em que Frederico II explicitava ao rei de Castilha a vontade de aliar-se a ele para levar adiante uma ação comum contra a conduta do papa:

"Pensantes pure dilectionis affectum, quem ad vos ex antique memoria unitatis et moderni temporis consideratione habemus, indubie credimus, quod sicut vos sincere diligimus, ita nos vice mutua diligatis $[\ldots]$..”

"Pensantes amoris affectum, quem ad vos semper habuimus hactenus et habemus illesum firmiter credimus, ut sicut nos honorem vestrum et commoda libenter amplectimur, sic nos vice mutua diligatis $[\ldots] ., 23$

Os dois exemplos mostram bem o uso intenso das antologias por parte dos idealizadores dos textos, mas não permitem resolver plenamente um problema: quem os redigiu foram os notários a serviço do tribuno ou o próprio tribuno, que de formação era notário e que na produção privada se mostra bastante capaz de elaborações retóricas do gênero? Provavelmente nunca o saberemos, embora se possa muito bem refletir sobre o fato de que, no âmbito da produção epistolar produzida por Cola a título pessoal, reempregos tão evidentes não foram identificados até o momento. ${ }^{24}$ Devemos pensar, então, que os textos desse documento não são tanto fruto de uma particular habilidade literária de Cola quanto, antes, um produto elaborado na chancelaria da comuna por meio de instrumentos que, em seu âmbito, eram colocados à disposição dos funcionários. ${ }^{25}$ Portanto, pode-se muito bem relacionar tal documentação às práticas chancelerescas comunais de reempregos encontrados nos séculos XII e XIII com as Variae de Cassiodoro e no XIV com as summae dictaminis, e, pelo menos desse ponto de vista, ela torna a cultura do tribuno muito menos excepcional do que se havia pensado até agora. 


\section{Reempregos textuais no tardo Trecento}

Os reempregos do tardo Trecento esclarecem ainda melhor o que afirmamos. Interessa-nos, aqui, um grupo de quatro cartas públicas provenientes da comuna dos Reformatores reipublice entre 1360 e $1367 .{ }^{26}$ Conservadas junto com outras em um mesmo registro, elas são endereçadas aos líderes da comuna de Florença e têm o objetivo de informá-los sobre a atuação dos senadores que terminaram seu mandato, alguns dos quais (mas talvez isso valha para todos) acabaram sendo enviados a Roma justamente da cidade toscana. Começa-se por um relato sobre as atividades políticas e sobre os méritos do senadores, chegando-se, na seção dispositiva, a informar os destinatários da cessação de seu encargo, para concluir, enfim, com a explicitação dos laços de amizade entre as duas cidades. É sobretudo a parte laudativa desses documentos que carece de uma retórica complexa, persuasiva e já posta bastante à prova, e foi precisamente nessas seções que os notários da comuna decidiram combinar textos de uma das novas summae dictaminis com os bem conhecidos textos de Cassiodoro. Sirva de amostra o texto de um documento de 1363, centrado na atuação do senador Guelfo Pugliesi da Prato e totalmente comparável aos outros também do ponto de vista da praxe compositiva:

"Viri magnifici et amici carissimi, equitati videtur accommodum, si efficaci actione laudatis, digna meritis vicissitudo prestatur. Consonum rationi dinoscitur, si famosos sui laboris fructus accipiant qui in comissis eis offitiis laudabile se gesserunt. Sane quantum favoris, quantumque retributionis et premii viro magnifico domino Guelfo de Pulgensibus de Prato militi, Dei gratia Urbis Alme dudum senatori illustri, amico nostro carissimo debeatur, in sui regiminis amministratione contingituret post hec eius famosa probitas indicat, ac eius opera laudabilia manifestant. Meretur etiam ratione multiplici favore, Romanorum attolli. Nam ipse vir utique probate virtutis et magne prudentie vir etiam alti consilii et industrie circumspecte, senatus Urbis officium utiliter et honorifice, viriliter et sapienter exercens, per decurso semestri tempore urbem Romanam, in quietis et pacis otio, sub virga equitatis et iustitie lima rexit. Et cuncta cum libra eque lancis appendens, auxit rempublicam satis amplis et felicibus inclementis (sic!). Tanta qui etiam se continentie virtute succinsit, ut equitatem et institueret monitis, et doceret exemplis. Faciliter enim, quod est rectum et iustum iudex innocens persuadet, sub cuius laudabili conversatione pudet moras probabiles non habere. Qui semper scelus exorreat, si monitorem sui complicem videt? Frustra personam severitatis ficte se induit, cum avarus pecunie ambitus dissuadet, cum legibus parcendum censet iniustus." 27

"Aequitati videtur accomodum si efficaci actione laudatis digna moribus vicissitudo praestetur. Habet enim suam gloriam, qui pensatis excubiis militarem noscitur promovere fortunam."

"Quid favoris, quidve retributionis et premii [...] notarius apud sedem apostolicam et celsitudinem regiam mereatur, in sue devotionis 
claritate colligitur, et preter hoc eius famosa et experta probitas indicat ac ipsius laudabilia merita manifestant. Meretur enim ratione multiplici gratia dicte sedis attolli. Nam ipse vir utique probitate (sic! = probate) virtutis et eminentis scientie vir et magni consilii et industrie circumspecte predecessoribus nostris Romanis pontificibus ac nobis et ecclesie romane valde fideliter et multum ultiliter longo tempore sine intermissione servivit."

"Vixit tanta continentia, ut aequitatem et institueret monitis et doceret exemplis. Facilis enim recti persuasor est innocens iudex, sub cuius praedicabili conversatione pudet mores probabiles non habere. Quis enim vereatur scelus, cuius in suggestu gremii complicem videt? In cassum personam fictae severitatis inducit, cum avarus pecuniae ambitum dissuadet, cum legibus parendum censet iniustus." ${ }^{28}$

O elogio de Guelfo é um mosaico: ele começa com a reelaboração de uma Varia de Cassiodoro destinada a notificar, em 534, a nomeação de um regendarius, um dos oficiais que controlavam o sistema postal público, transformando as alusões à fortuna militar em um feliz cumprimento mais geral do próprio encargo. $\mathrm{O}$ texto prossegue, mas sem nenhuma solução de continuidade, tomando por referência uma carta da summa de Riccardo da Pofi, dictator pontifício que viveu no Duecento, na qual um papa, quase certamente Clemente IV (1265-1268), recomenda um notário a seu interlocutor, talvez um rei. Aqui as mudanças dizem respeito sobretudo às referências à pessoa elogiada: as qualidades intelectuais do notário de Ricardo da Pofi tornam-se, no documento, virtudes políticas (de scientia a prudentia), ampliadas, por sua vez, através de uma série de imagens metafóricas de efeito (pacis otium, iustitie lima, virga equitatis). Torna-se enfim às Variae, desta vez copiando sem mudanças substanciais parte da famosa carta em que Cassiodoro havia proposto um elogio de si mesmo e de sua própria atividade em nome de Teodorico e voltando-se ao Senado romano. É um ótimo exemplo, esse, da persistência de modelos antigos mesmo depois do aparecimento de novos e, sobretudo, da convivência de ambos no mesmo ambiente. Em outras palavras, a análise arqueológica do documentos mostra bem, nesses casos, a estratificação cultural na base de cada documento.

\section{Conclusões}

As citações implícitas e as reelaborações de modelos epistolares identificados na documentação da comuna romana assumem um valor particular se observadas no contexto mais amplo das atividades escriturais da chancelaria considerada. Elas têm algo a dizer com respeito à cultura do notário que concebeu cada texto e fornecem-nos também informações mais gerais sobre as práticas em uso no âmbito da chancelaria. Particularmente, permitem-nos reconstruir a presença de uma determinada instrumentação de escritura nos ambientes capitolinos e compreender seus desenvolvimentos num período mais vasto.

Durante as primeiras décadas de vida da comuna romana, os funcionários recrutados a seu serviço, dentre os quais seguramente havia notários provenientes das fileiras dos scriniarii de Roma, tiveram uma tarefa dificílima: identificar modelos aptos a construir uma retórica que fosse capaz de competir com a do poder universal pontifício. Tratava-se de um verdadeiro e próprio desafio, porque tais notários, que haviam desenvolvido as próprias competências, no curso do alto medievo, nos 
ambientes pontifícios do Laterano, deviam agora tentar distanciar-se deles. Num primeiro momento, quando as relações entre os imperadores germânicos e Roma tornaram-se mais intensas, foi a retórica imperial que se prestou a tal fim, mas já por volta de 1188, e provavelmente já algum tempo antes, a chancelaria do Senado exumou a coletânea de cartas de Cassiodoro, referindo-se constantemente a ela ao longo de todo o arco de sua vida. É fácil compreender as razões específicas dessa escolha: por mais que estivessem ligadas à Itália dos reis ostrogodos — uma Itália, porém, observada com filtros muito diversos dos modernos e certamente alheia ao próprio conceito de Medievo, que, é óbvio, não existia - as Variae ilustravam, de maneira articulada e muitas vezes com tons particularmente laudativos, a cidade de Roma, o Senado e sua administração, as relações entre instituições laicas e eclesiásticas. ${ }^{29}$

Em seguida à afirmação da produção epistolar dos grandes dictatores do Duecento como modelo indiscutível de escritura em âmbito político no fim daquele século, os funcionários da Urbe mostraram uma boa capacidade receptiva perante esses novos ventos culturais e acolheram os instrumentos que veiculavam tais modelos: as summae dictaminis, das quais seguramente recordavam a 'imperial' de Pier della Vigna e a 'papal' de Riccardo da Pofi. Não se tratava, porém, de uma solução de continuidade em relação ao período mais antigo, porque, tal como vimos, mas cabe explicitar, dada a suposta "singularidade" de Cola di Rienzo, os notários da comuna de Roma já haviam várias vezes colhido as vantagens da retórica dos poderes universais, Sacro Império Romano incluso, como vimos para o ano de 1188. As summae não fizeram mais do que reforçar e melhorar a já consolidada habilidade retórica de um grupo profissional que de pronto se vira competindo com a retórica dos dois poderes universais, em particular com o papado. Quando Cola, primeiramente notário comunal e depois Tribunus, levou continuamente em conta as cartas de Pier della Vigna — ou seja, de Frederico II — em sua aventura política, não fez mais do que seguir por uma estrada aberta dois séculos antes por seus antigos colegas. É de fato altamente provável que a ideologia "imperial" da primeira comuna romana tenha sido construída no âmago daqueles notários romanos que já desde os anos quarenta haviam buscado o favor do império, para ser depois refinada no fim do século XII por quem deles recebesse a investidura não dos papas, como de costume, mas dos imperadores germânicos, assumindo o título de scriniarius Sacri Romani Imperii. ${ }^{30}$ Em suma, a análise das citações, ou melhor, dos reempregos textuais na chancelaria, elevadas à posição de verdadeiras e próprias fontes históricas, oferece ao estudioso mais de uma perspectiva para compreender como, ao longo do tardo medievo, foram formando-se novas comunidades textuais laicas, neste caso, a comunal do Senado.

No contexto da Itália comunal e senhoril, a comuna romana não é o único caso que podemos estudar desse ponto de vista. Para muitas cidades, dispomos de uma documentação epistolar pública abundante, em alguns casos até mais sólida do que a de Roma. ${ }^{31}$ Tal documentação é afim àquela analisada até aqui, seja pela cultura daqueles que a produziram, seja pelas técnicas redacionais e formais, que, ao longo do tempo (em particular no século XII), sofreram os efeitos dos mesmos processos, tornando-se particularmente homogêneas. ${ }^{32}$ Será então necessário, para levar a um nível mais geral as considerações apresentadas, recolher informações sobre a fisionomia social e sobre o grau de formação dos funcionários redatores das atas, sobre a circulação livresca da área e sobre os seus ambientes chancelerescos e notariais. ${ }^{33}$ Ficarão claros, dessa maneira, alguns aspectos das práticas de chancelaria dos casos citadinos considerados (e os modelos de escritura não serão necessariamente idênticos aos identificados para Roma, 
pelo menos no que concerne ao Trecento). Ademais, conseguiremos compreender melhor as razões da afirmação e da sobrevivência de determinados modelos em um ambiente mais do que em outro, as relações entre um determinado tipo de conhecimentos e as atividades profissionais a que se vinculam, por fim, a eventual especificidade da Itália comunal no panorama europeu mais amplo. Esse campo de pesquisa, em suma, revela-se ao mesmo tempo profícuo e ainda pouco praticado: o autor espera que tais reflexões tenham conseguido sensibilizar o leitor sobre um tipo de testemunho geralmente considerado repetitivo e rígido, quando, pelo contrário, ele é rico em preciosas sugestões (por meio precisamente das citações) para a história da cultura.

\footnotetext{
${ }^{1}$ Texto inédito em português. Publicação original: La citazione in cancelleria. Il comune di Roma nel medioevo, «Parole rubate. Rivista internazionale di studi sulla citazione» 19 (2019), pp. 55-79. Agradecemos ao Prof. Dr. Adriano Scatolin, do Departamento de Letras Clássícas e Vernáculas da Universidade de São Paulo (DLCV-USP), especialista em Retórica Antiga, que gentilmente traduziu o texto.

${ }^{2}$ Sobre o documento público, ver A. Pratesi, Genesi e forme del documento medievale, Roma, Jouvence, 1999, pp. 39-46 e G. Nicolaj, Lezioni di diplomatica generale, vol. I, Istituzioni, Roma, Bulzoni, 2007, pp. 22-26 e pp. 98-134; para abordagens diferentes em relação à diplomática mais tradicional, ver V. Crescenzi, La rappresentazione dell'evento giuridico. Origini e struttura della funzione documentaria, Roma, Carocci, 2005. Sobre a cultura epistolar do medievo tardio, ver Le 'dictamen' dans tous ses états. Perspectives de recherches sur la théorie et la pratique de l' 'ars dictaminis' (XI $I^{e}-X V^{e}$ siècles), Actes du Colloque International de Paris, 5-6 Juillet 2012, études réunies par B. Grévin et A.-M. Turcan-Verkerk, Turnhout, Brepols, 2015.

${ }^{3}$ Ver B. Grévin, Rhétorique du pouvoir médiéval. Les Lettres de Pierre de la Vigne et la formation du langage politique européen (XIII-XV siècle), Roma, École Française de Rome, 2008.

${ }^{4}$ Ver P. Chastang, L'archéologie du texte médiéval. Autour de travaux révents sur l'écrit au Moyen Âge, in "Annales. Histoire, Sciences sociales", LXIII/2, 2008, pp. 245-269.

${ }^{5}$ Ver B. Grévin, Rhétorique du pouvoir médiéval. Les Lettres de Pierre de la Vigne et la formation du langage politique européen (XIII-XV siècle), cit., pp. 539-888.

${ }^{6}$ Ver $i b .$, pp. 750-858. Sobre a Itália comunal e senhoril, ver J.-C. Maire Vigueur e E. Faini, Il sistema politico dei comuni italiani (secoli XII-XIV), Milano-Torino, Bruno Mondadori, 2010 e Signorie cittadine nell'Italia comunale, a cura di J.-C. Maire Vigueur, Roma, Viella, 2013; C. Wickham, Sonnambuli verso un nuovo mondo. L'affermazione dei comuni italiani nel XII secolo, Roma, Viella, 2017. Para a relação entre dictamen e história das comunas, é forçoso começar por F. Hartmann, Ars dictaminis. Briefsteller und verbale Kommunikation in den italienischen Stadtkommunen des 11. bis 13. Jahrhunderts, Ostfildern, Thorbecke, 2013.

${ }^{7}$ Ver B. Grévin, Rhétorique du pouvoir médiéval. Les Lettres de Pierre de la Vigne et la formation du langage politique européen (XIII-XV siècle), cit., pp. 803-823. Sobre os paradigmas historiográficos e sobre a documentação romana tardomedieval, ver C. Carbonetti, Le scritture del comune di Roma nel medioevo, in Roma e il suo territorio nel medioevo. Le fonti scritte fra tradizione e innovazione, Atti del Convegno internazionale di studio dell'Associazione italiana dei Paleografi e Diplomatisti (Roma, 25-29 ottobre 2012), a cura di C. Carbonetti, S. Lucà e M. Signorini, Spoleto, Fondazione Centro Italiano di Studi sull'Alto Medioevo - CISAM, 2015, pp. 293-342 e D. Internullo, Ai margini dei giganti. La vita intellettuale dei romani nel Trecento, Roma, Viella, 2016, pp. 3-14.

${ }^{8}$ Sobre a história da Roma comunal, ver J.-C. Maire Vigueur, L'altra Roma. Una storia dei romani all'epoca dei comuni (sec. XII-XIV), trad. ital. di P. Garbini, Torino, Einaudi, 2011 e C. Wickham, Roma medievale. Crisi e stabilità di una città (900-1150), Roma, Viella, 2013, pp. 496-520.

${ }^{9}$ Sobre os scriniarii e sua cultura, ver C. Carbonetti Vendittelli, Tabellioni e scriniari a Roma tra IX e XI secolo, in "Archivio della Società Romana di Storia Patria", CII, 1979, pp. 271-300; P. Radiciotti, La curiale romana nuova: parabola discendente di una scrittura, ivi, CXII, 1989, pp. 39-113 e CXX, 1997, pp. 45-64; S. Ammirati, Testi e 'marginalia' in libri prodotti a Roma alla fine dell'alto medioevo:
} 
riflessioni sulla cultura degli 'Scriniarii Sanctae Romanae Ecclesiae', in Roma e il suo territorio nel medioevo. Le fonti scritte fra tradizione e innovazione, cit., pp. 343-363; C. Carbonetti Vendittelli, Il palatium Lateranense come risorsa: gli scrittori di documenti a Roma tra VIII e XII secolo, in La mobilità sociale nel Medioevo italiano 3. Il mondo ecclesiastico (secoli XII-XV), a c. di S. Carocci e A. De Vincentiis, Roma, Viella, 2017 pp. 75-92.

${ }^{10}$ Ver I. Lori Sanfilippo, 'Constitutiones et Reformationes' del Collegio dei notai di Roma (1446). Contributi per una storia del notariato romano dal XIII al XV secolo, Roma, Società Romana di Storia Patria, 2007, pp. 8-14.

${ }^{11}$ C. Carbonetti, Le scritture del comune di Roma nel medioevo, cit., p. 295.

${ }^{12}$ Para um primeiro exame das edições ou fontes que coligem os textos de tal documentação, ver D. Internullo, Ai margini dei giganti. La vita intellettuale dei romani nel Trecento, cit., pp. 412-423.

${ }^{13} \mathrm{O}$ documento, transmitido em cópia pelo Liber Censuum, do camarário pontificio Cencio (futuro papa Onório III), foi objeto de interpretações diversas: ver J.-C. Maire Vigueur, L'altra Roma. Una storia dei romani all'epoca dei comuni (sec. XII-XIV), cit., pp. 277-278.

${ }^{14}$ Sobre o preâmbulo (definido também como arenga, na terminologia diplomatística), ver H. Fichtenau, Arenga. Spätantike und Mittelalter im Spiegel von Urkundenformeln, Graz-Köln, Verlag Hermann Böhlaus, 1957; S. Barret e B. Grévin, "Regalis excellentia": les préambules des actes des rois de France au XIVe siècle (1300-1380), Paris, École des Chartes, 2014, p. 17.

${ }^{15}$ Codice diplomatico del Senato romano, a cura di F. Bartoloni, vol. I (unico pubblicato), Roma, Tipografia del Senato, 1948, pp. 69-74 (nr. 42) e Acta Imperii selecta. Urkunden Deutscher Könige und Kaiser, Hrsg. von J.F. Böhmer, Verlag der Wagnerischen Universitäts-Buchhandlung, 1870, pp. 117-118 (nr. 125). Ver J. Petersohn, Der Vertrag des Römischen Senats mit Papst Clemens III (1188) und das Pactum Friedrich Barbarossas mit den Römern (1167), in "Mitteilungen des Instituts für österreichische Geschichtsforschung" LXXXII, 1974, pp. 289-337.

${ }^{16}$ Petersohn (ver nota precedente) considera plausível que o modelo do documento senatorial não tenha sido exatamente o privilégio para São Bartolomeu, mas, antes, outro documento, hoje perdido, mas conservado então no Capitólio, concernente ao tratado que os romanos haviam estipulado com o imperador em 1167 e que continha um preâmbulo de todo análogo. A hipótese é de fato convincente, mas não se pode excuir que os chanceleres comunais, que ao longo do Duecento, e talvez mesmo antes, provinham de uma família (De Insula) estabelecida na Isola Tiberina muito ligada à igreja de S. Bartolomeu, tenham recorrido precisamente ao documento conservado. Abordaremos a questão em outro trabalho.

${ }^{17}$ Codice diplomatico del Senato, cit., p. 71 (nr. 42) e M. A. Cassiodoro, Variarum libri XII, cura et studio A. J. Fridh, Turnhout, Brepols, 1973, pp. 115-116 (III 25). Negrito nosso. Para um comentário histórico exaustivo das Variae, ver a edição organizada por A. Giardina, Roma, "L'Erma" di Bretschneider, 2014-2016, voll. II (libri III-V), III (libri VI-VI), IV (libri VIII-X) e V (libri XI-XII).

${ }^{18}$ Codice diplomatico del Senato, cit., pp. 177-180 (nr. 108, em que se remete ao documento nr. 72) e M. A. Cassiodoro, Variarum libri XII, cit., pp. 330-332 e pp. 426-428 (VIII, 24 e XI, 2). Negrito nosso.

${ }^{19}$ Ver D. Internullo, Ai margini dei giganti. La vita intellettuale dei romani nel Trecento, cit., pp. 192215, 366-382.

${ }^{20}$ Ver T. di Carpegna Falconieri, Cola di Rienzo, Roma, Salerno, 2002, pp. 44-45.

${ }^{21}$ Briefwechsel des Cola di Rienzo, hrsg. von K. Burdach und P. Piur, Berlin, Weidmann, 1912, vol. III, pp. 1-4 (nr. 1) e L'epistolario di Pier della Vigna, a cura di E. D'Angelo, Soveria Mannelli, Rubbettino, 2014, pp. 259-261 e p. 395 (Summa dictaminis II, 1 e II, 45). Negrito nosso. O documento atribuído a Cola di Rienzo circulou sob o nome coletivo dos embaixadores romanos (entre seus autores deveria estar Lello Tosetti, amigo de Francesco Petrarca): ver B. Grévin, Rhétorique du pouvoir médiéval. Les Lettres de Pierre de la Vigne et la formation du langage politique européen (XIII-XV siècle), cit., pp. 805-806. Modelo comum aos romanos e a Pier della Vigna parece ser o Exultet pascal: agradecemos Enrico Faini pela observação.

${ }^{22}$ Briefwechsel des Cola di Rienzo, cit., vol. III, pp. 61-62 (nr. 21) e L'epistolario di Pier della Vigna, cit., pp. 114-119 (Summa dictaminis I, 8). Ver B. Grévin, Rhétorique du pouvoir médiéval. Les Lettres de Pierre de la Vigne et la formation du langage politique européen (XIII-XV siècle), cit., pp. 813-815. Negrito nosso.

${ }^{23}$ Briefwechsel des Cola di Rienzo, cit., vol. III pp. 122-123 (nr. 33) e L'epistolario di Pier della Vigna, cit., pp. 138-141 (Summa dictaminis I, 15).

${ }^{24}$ Ver B. Grévin, Rhétorique du pouvoir médiéval. Les Lettres de Pierre de la Vigne et la formation du langage politique européen (XIII-XV siècle), cit., pp. 817-822. 
${ }^{25}$ Por outro lado, referindo-se ao tribunado de Cola di Rienzo, o cronista conhecido como Anônimo Romano relata que "o tribuno dispunha de muitos escritores e muitos ditadores, os quais não cessavam, dia e noite, de escrever cartas. Muitos eram os mais famosos do território de Roma" (cf. Anônimo Romano, Cronica, a cura di G. Porta, Adelphi, Milano 1979, p. 162).

${ }^{26}$ Provieram, respectivamente, dos reformatores reipublice, o primeiro (10 de outubro de 1360); dos reformatores e dos alferes e prelados da Felix societas balistariorum et pavesatorum, o segundo (30 de maio de 1363); de todas essas figuras mais um senador estrangeiro, o terceiro (30 de novembro de 1363); e novamente dos reformatores, alferes e prelados, o quarto (28 de abril de 1367).

${ }^{27}$ Florença, Archivio di Stato, Capitoli, Registri, 16, ff. 99v-100r.

${ }^{28}$ Respectivamente M. A. Cassiodoro, Variarum libri XII, cit., p. 450 (XI, 29); Riccardo da Pofi, Summa dictaminis (62), in Paris, BNF, lat. 14766, ff. 144v-145r; M. A. Cassiodoro, Variarum libri XII, cit., pp. 13-16 (I, 4).

${ }^{29}$ Ver A. Giardina, Cassiodoro politico, Roma, "L'Erma" di Bretschneider, 2006; F. Cardini, Cassiodoro il grande. Roma, i barbari e il monachesimo, Milano, Jaca Book, 2009; M. S. Bjornlie, Politics and Tradition between Rome, Ravenna and Constantinople. A Study of Cassiodorus and the "Variae", $527-$ 554, Cambridge, Cambridge University Press, 2012. Um manuscrito do século XIII contendo as Variae e de ambiente romano é o Paris, BNF, lat. 2790, sobre o qual ver Il libro miniato a Roma nel Duecento. Riflessioni e proposte, a cura di S. Maddalo, con la collaborazione di E. Ponzi, Roma, ISIME, 2016, pp. $131,278,358,598-599$.

${ }^{30}$ Sobre estes, ver J. Petersohn, Kaiserliche Skriniare in Rom bis zum Jahre 1200, in "Quellen und Forschungen aus Italienischen Archiven und Bibliotheken", LXXV, 1995, pp. 1-31. Considere-se também que por volta de 1200 o chanceler do Senado Cencius de Insula tem dois parentes, dos quais um, Adam, é sacri Senatus scriba e o outro, Romanus, é scriniarius sacri Romani Imperii: BAV, Archivio del Capitolo di S. Pietro, caps. 26, fasc. 313 n. 6.

${ }^{31}$ Ver La corrispondenza epistolare in italia, Convegno di studio (Trieste, 28-29 maggio 2010), a cura di M. Davide, Trieste, École Française de Rome - CERM, 2018, vol. 1 (secoli XII-XV) e P. Merati, Elementi distintivi nella documentazione signorile, in Signorie cittadine nell'Italia comunale, cit., pp. 421-438. Numerosi spunti ora anche in E. Faini, Italica gens. Memoria e immaginario politico dei cavalieri cittadini (secoli XII-XIII), Roma, Viella, 2018.

${ }^{32}$ Ver C. Carbonetti, Le scritture del comune di Roma nel Medioevo, cit., pp. 336-342.

${ }^{33}$ Para Florença, ver I. Ceccherini-T. De Robertis, 'Scriptoria' e cancellerie nella Firenze del XIV secolo, in Scriptorium. Wesen - Funktion - Eigenheiten, Comité international de paléographie latine, XVIII / Internationaler Kongress St. Gallen 11.-14. September 2013, Hrsg. von A.Nievergelt, R. Gamper, M. Bernasconi, B. Ebersperger, E. Tremp, München, Bayerische Akademie der Wissenschaften, 2015, pp. 141-169. Para Bolonha, ver M. Giansante, Retorica e politica nel Duecento. I notai bolognesi e l'ideologia comunale, Roma, Istituto Storico Italiano per il Medio Evo, 1999. 